\title{
Response to "The Buteyko Technique: News"
}

Jean-François Masse, DMD, MSc, Diplomate, ABDSM

Editor-in-Chief Journal of Dental Sleep Medicine

Universite Laval, Quebec City, Quebec, Canada

Dear Mr. Mckeown,

Thank you for your timely letter, as harmonizes with this month's paper from Victor Lai, Dr. Jayne Carberry and Dr. Danny Eckert. ${ }^{1}$

In your well referenced letter, you point out the importance of breathing in the control of obstructive sleep apnea. I could not agree more.

The objective of my editorial was to point out the absence of scientific evidence regarding the Buteyko technique and the need for studies supporting that specific technique.

Your commitment to your field of interest is impressive and demands respect. Your impact would be dramatically increased if one could come up with good studies on the Buteyko technique. I will be looking forward to these.

\section{CITATION}

Masse, JF. Response to "The Buteyko technique: News". J Dent Sleep Med. 2019;6(2)

\section{REFERENCES}

1. Lai V, Carberry JC, Eckert DJ. Sleep Apnea Phenotyping: Implications for Dental Sleep Medicine. J Dent Sleep Med. 2019;6(2)

\section{SUBMISSION AND CORRESPONDENCE INFORMATION}

\section{Accepted for publication March 31, 2019}

Address correspondence to: Jean-François Masse, Professor, Universite Laval, 2780 Masson \#200, Quebec City, QC, G1P 1J6, Canada; Tel: 418871-1447; Fax: 418871-4983; Email: jean-francois.masse@fmd.ulaval.ca 